\title{
臨界圧近傍における限界熱流束の特性 Characteristics of Critical Heat Flux at Near-Critical Pressure
}

\author{
$\bigcirc$ 馬渡 峻史（九大院） 吉住 健（電源開発） \\ 正 森 英夫（九大）正 仮屋 圭史（九大） 正 大野 正規（九大）
}

Takashi Mawatari, Ken Yoshizumi, Hideo Mori, Keishi Kariya and Masaki Ohno

Kyushu University, 774 Motooka, Nishi-ku, Fukuoka 819-0395

Electric Power Development Co.,Ltd, 6-15-1 Ginza, Chuo-ku, Tokyo 104-8165

\begin{abstract}
Supercritical pressure water cooled reactor (SCWR), which is operated at supercritical pressure, is one of the next generation reactors for the purpose of improving economic efficiency and safety. In the SCWR, water pressure passes the critical pressure during startup, shutdown or in case of loss of coolant accident (LOCA). In the near-critical pressure region which the pressure slightly below the critical pressure, critical heat flux (CHF) condition tends to occur at relatively low heat flux and then there is a risk of serious damage of fuel rod due to abrupt rise of surface temperature. In this study, experiments on CHF at near-critical pressure in vertical upward flow inside a tube were conducted to clarify characteristics of CHF at near-critical pressure.
\end{abstract}

Key Words: Critical Heat Flux, Near-critical pressure, Flow Boiling, Characteristics

\section{1.はじめに}

原子炬プラントの熱効率向上とシステムの簡素化などを 目的とした超臨界圧水冷却炉（SCWR）の開発が国際的に 進められている(1).SCWR では従来型原子炉よりも高温高 圧である運転圧力 $25 \mathrm{MPa}$ (換算圧力 1.1 ），冷却水炉心出

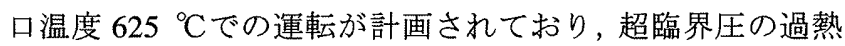
蒸気がタービンへ送られる。

SCWR では, 起動停止時などに超臨界圧と大気圧の間で 圧力を変化させる. 臨界圧力に近い业臨界圧力域では, 膜 沸騰による限界熱流束 (CHF) 状態が発生しやすく, 燃料 棒が損傷する危険性がある。そのため，このような圧力域 における CHF 特性の解明が SCWR の安全設計・運用のた めに不可欠であるが，これに関する研究は少ない(2).

本研究では，臨界圧近傍域を対象とした限界熱流束につ いて試験を行い, 特性の解明を試みた。

\section{2. 試験装置・方法}

試験装置は既設の強制対流試験ループ(3)である. 試験に は内径 $4.4 \mathrm{~mm}$, 外径 $6.4 \mathrm{~mm}$ の円管を用いた. 有効加熱長 は $2000 \mathrm{~mm}$ で, 長さ方向 $50 \mathrm{~mm}$ 間隔で計 39 本の熱電対が 管外壁に取り付けられている。試験は, 流量, 圧力, 試験 体入口流体バルクエンタルピーを一定に保ち，熱流束を段 階的に上昇させる熱流束制御試験と, 他の条件を一定に保 ち圧力を段階的に上昇させる圧力制御試験の 2 通りを行っ た. 試験条件を表 1 に示す. 試験流体には水の模擬流体と して HCFC22 および HFC134a を使用し, 試験圧力として換

Table1 Experimental Conditions

\begin{tabular}{|c|c|c|c|c|}
\hline $\begin{array}{c}\text { Mass flux } \\
G \\
\mathrm{~kg} /\left(\mathrm{m}^{2} \cdot \mathrm{s}\right) \\
\end{array}$ & $\begin{array}{c}\text { Pressure } \\
P(P / P c) \\
\mathrm{MPa} \\
\end{array}$ & $\begin{array}{c}\text { Heat } \\
\text { flux } \\
q \\
\mathrm{~kW} / \mathrm{m}^{2} \\
\end{array}$ & $\begin{array}{c}\text { Inlet bulk } \\
\text { enthalpy } \\
h_{\mathrm{b}, \mathrm{in}} \\
\mathrm{kJ} / \mathrm{kg} \\
\end{array}$ & $\begin{array}{l}\text { Number } \\
\text { of data }\end{array}$ \\
\hline \multicolumn{5}{|c|}{ Increasing heat flux method, using HCFC22, HFC134a } \\
\hline$\stackrel{400}{1}$ & $\begin{array}{c}4.8,3.9(0.96) \\
\mid \\
4.95,4.02(0.99) \\
\end{array}$ & $8-60$ & $255-363$ & 315 \\
\hline \multicolumn{5}{|c|}{ Increasing pressure method, using HFC134a } \\
\hline$\left.\right|_{1000} ^{400}$ & $\begin{aligned} 3.9 & -4.5 \\
(0.961 & -1.109)\end{aligned}$ & $20-42$ & $320-331$ & 31 \\
\hline
\end{tabular}

算圧力 $0.96-0.99$ の範囲で圧力を設定した.

\section{3. 試験結果と検討}

図 1 に試験結果の一例を示す。図に示すように, 試験体 壁温が流れ方向に急上昇する点をその流量・圧力・熱流束 条件の CHF 状態発生点とし, その点のバルクエンタルピー $h_{\mathrm{b}}$ と熱平衡クオリティ $x_{\mathrm{b}}$ をそれぞれ限界エンタルピー $h_{\mathrm{CHF}}$ と限界クオリティ $x_{\mathrm{CHF}}$ とした.クオリティはサブクール域 まで拡張し，その場合負の值となる。

HCFC22 の試験結果を図 2(a)と(b)に示す．上下段はそれ ぞれ，限界熱流束 $q_{\mathrm{CHF}}$ および熱流束を流量と潜熱で除して 無次元化した限界ボイリング数 $B o_{\mathrm{CHF}}$ を, クオリティに対 し整理したものである。図中，実線あるいは破線で，より 低い高圧域に適用される森らの式(4)による予測值を示す。

あるクオリティにおいて，限界熱流束は，圧力の上昇と ともに減少し, 流量の上昇とともに增大している。これに 対し, 限界ボイリング数では, 各条件の影響は比較的小さ W.

限界ボイリング数とクオリティの関係の傾向から, 臨界 圧近傍における CHF 特性は, 次の 3 つの特性域に分類され る.クオリティの低い方から順に,クオリティが約-0.5 - - 0.3 より小さい領域における一次関数的変化を示寸特性域 F,

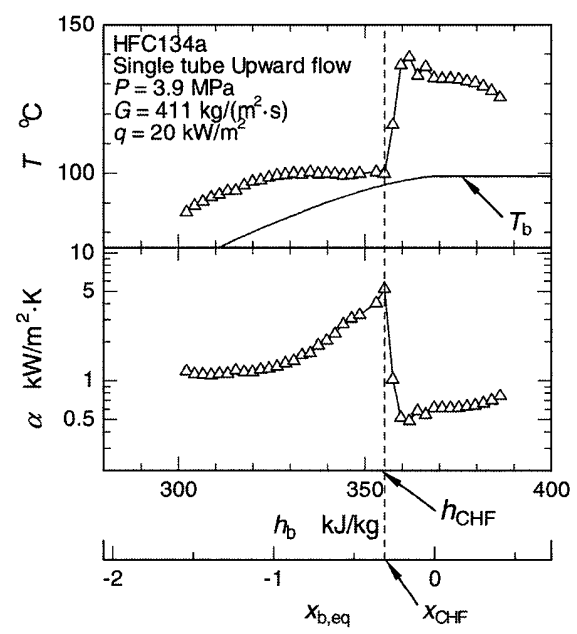

Fig.1 Definition of CHF condition; critical enthalpy $h_{\mathrm{CHF}}$ and critical quality $x_{\mathrm{CHF}}$ 


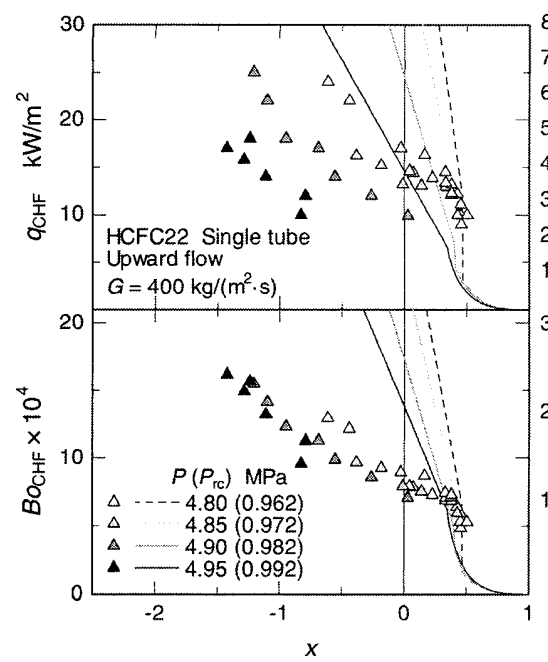

(a) $\mathrm{G}=400 \mathrm{~kg} /\left(\mathrm{m}^{2} \cdot \mathrm{s}\right)$

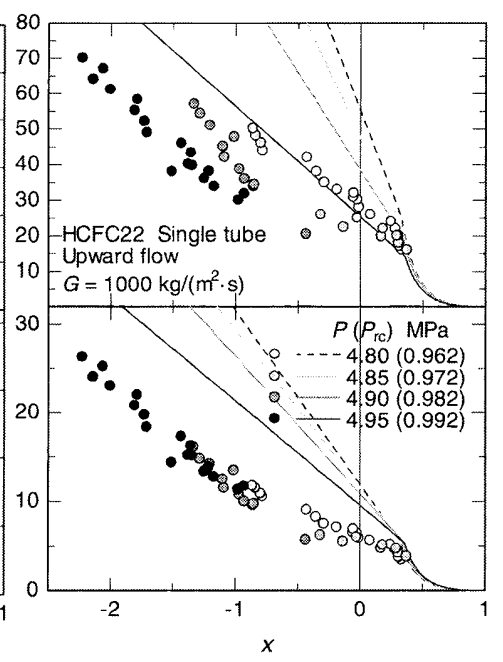

(b) $\mathrm{G}=1000 \mathrm{~kg} /\left(\mathrm{m}^{2} \cdot \mathrm{s}\right)$

Fig.2 Critical heat flux $q_{\mathrm{CHF}}$ and critical boiling number $B o_{\mathrm{CHF}}$ vs. quality $x$ (HCFC22, increasing heat flux method)

高流量条件でクオリティが約-0.3 以上から湿り蒸気域低ク オリティまでの条件でみられる，クオリティに対する $B o_{\mathrm{CHF}}$ の勾配が小さい特性域 D1, そして低クオリティ以上 の領域の特性域 D2である。各特性域における $\mathrm{CHF}$ 発生機 構はそれぞれ膜沸騰, ドライアウト-膜沸騰の遷移, ドライ アウトと考えられる.

$\mathrm{F}$ 域については，以下の理由から，さらに2つの特性域 F1，F2 に区分される．まず，図 3 に示す压力制御の試験結 果から，流量に関わらずおよそ $4 \mathrm{MPa} て ゙$ 限界エンタルピー が極小值をとることがわかった．この圧力前後での特性変 化は，図 4 に示す膜沸騰発生への伝熱メカニズムの遷移過 程の変化に対応し，低圧側および高圧側をそれぞれ F2 と F1 域とすると，F2 域では DNBによる CHF 状態が生じる のに対し，F1 域では核沸騰を経ず液単相対流から直接膜沸 騰へ遷移している。この F1 域は，図 2 においては，ク才 リティ約 -1 以下の領域に相当し, 流量・圧力条件のほか 流体の種類を問わず直線状に整理される. 以上に述べた限 界熱流束およびボイリング数の特性を, 発生領域とメカ二 ズムを含め, Table.2に示す.

森らの式は比較的高圧（換算圧力 0.96）まで精度よく適 用可能であるが，D2 域を除いて，特にサブクール度の大き いF 域では試験結果を再現しない。

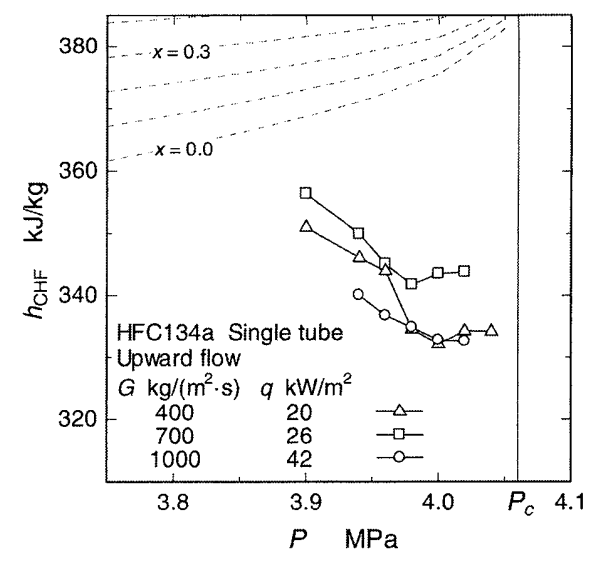

Fig.3 Critical enthalpy $h_{\mathrm{CHF}}$ vs. pressure $P$ (HFC134a, increasing pressure method)

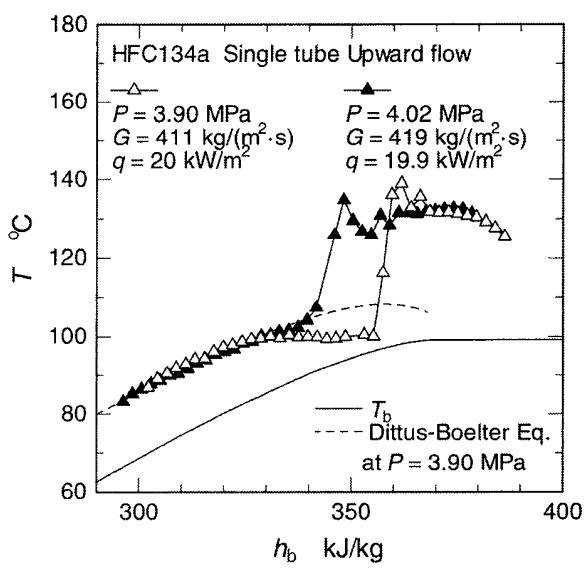

Fig.4 Difference of CHF in the subcooled liquid region

\section{4.まとめ}

臨界圧近傍における CHF を測定し，その特性を，発生機 構と特性の違いから 4 特性域に分類した。また，高サブク 一ル域の CHF は異なる傾向を示し, 従来の整理式では再現 できない.

\section{参考文献}

(1) Y.Oka and S.Koshizuka, JNST, 38 (2001), 1081-1089.

(2) D.C.Groeneveld et al., Nuclear Engineering and Design, 237 (2007), 1909-1922.

(3) H.Mori et al., JNST, 49 (2012), 373-383.

（4）森 英夫，他，機論 (B 編)， 65-639 (1999), 3748-3755.

Table2 Classification of the critical heat flux at near-critical pressure

\begin{tabular}{|c|c|c|c|c|}
\hline Regime & $q_{\mathrm{CHF}}$ vs. $x$ & $B o_{\mathrm{CHF}}$ vs. $x$ & Region & Mechanism \\
\hline F1 & $\begin{array}{l}q_{\mathrm{CHF}} \text { decreases linearly with } \\
\text { increase of } x . q_{\mathrm{CHF}} \text { decreases } \\
\text { with increase of } P \text { and } \\
\text { increases with increase of } G \text {. }\end{array}$ & $\begin{array}{l}B o_{\mathrm{CHF}} \text { increases } \quad \text { with } \\
\text { decrease of } x . \text { The } \\
\text { decreasing rate is linearly } \\
\text { and independent of } G \text { and } P \text {. }\end{array}$ & $\begin{array}{l}\text { At high } G \text { and } P \text { and in relatively } \\
\text { high subcooled region }(x<-1) \text {. The } \\
\text { region expands to low pressure and } \\
\text { flow rate at high heat flux. }\end{array}$ & $\begin{array}{l}\text { Film Boiling; } \\
\text { Departure from liquid } \\
\text { single-phase flow with- } \\
\text { out nucleate boiling. }\end{array}$ \\
\hline $\mathrm{F} 2$ & As same as F1. & $\begin{array}{l}B o_{\mathrm{CHF}} \text { decreases with } \\
\text { increase of } G \text { and } P \text { slightly. } \\
\text { The decreasing rate of } B o_{\mathrm{CHF}} \\
\text { with increase of } x \text { is linearly. }\end{array}$ & $\begin{array}{l}\text { At low } G \text { and } P \text { and in relatively low } \\
\text { subcooled region (about }-1<x<0 \text { ). } \\
\text { The region expands to low subcooled } \\
\text { and saturated region at high } G \text {. }\end{array}$ & $\begin{array}{l}\text { Film Boiling; } \\
\text { Departure } \\
\text { nucleate boiling. }\end{array}$ \\
\hline D1 & As same as F1. & $\begin{array}{l}B o_{\mathrm{CHF}} \text { depends on } G \text { and } P \text { as } \\
\text { same as } \mathrm{F} 2 . \text { The decreasing } \\
\text { rate of } B o_{\mathrm{CHF}} \text { with increase } \\
\text { of } x \text { is linearly and less } \\
\text { gradient than regimes } \mathrm{F} \text {. }\end{array}$ & $\begin{array}{l}\text { In near saturated region }(-0.5<x< \\
0.3) \text { at high } G \text {. At higher } q \text { than } \mathrm{D} 2 \text {. } \\
\text { The region reduces or dis appears at } \\
\text { low } G \text {. }\end{array}$ & $\begin{array}{l}\text { Transition between F2 } \\
\text { and D2 }\end{array}$ \\
\hline D2 & $\begin{array}{l}q_{\mathrm{CHF}} \text { increases with decrease } \\
\text { of } x \text { exponentially. }\end{array}$ & $\begin{array}{l}\text { The decreasing rate of } \mathrm{Bo}_{\mathrm{CHF}} \\
\text { with increase of } x \text { is } \\
\text { exponentially. }\end{array}$ & $\begin{array}{l}\text { At low } P \text {, in saturated region (about } x \\
>0.3 \text { ). }\end{array}$ & $\begin{array}{l}\text { Dryout; } \\
\text { Rupture of liquid film. }\end{array}$ \\
\hline
\end{tabular}

